\title{
INSTITUIÇÕES PARA UMA SOCIEDADE EQUITATIVA: A TEORIA DA JUSTIÇA IGUALITÁRIA DE RAWLS ${ }^{1}$
}

\author{
Percy B. Lehning \\ Erasmus University Rotterdam
}

\begin{abstract}
This paper intends to illustrate, by focusing on a central element of Rawls's strong egalitarian conception of justice, to wit, the design of the institutional frameworks of societies in line with what is required by justice as fairness, the following argument: that his radical theory of justice is still, and in fact even more so, relevant for our actual predicament. In sum, Rawls's ideas on the equal moral worth of free and equal persons, on "morals and markets", on empowerment and questions of access to the political process for each and every citizen, on "deliberative democracy" , on "democratic citizenship", on "the duty of public civility" , on "civic friendship" , on the basic shortcoming of utilitarianism, on political, social and economic inequalities, show us the choices to be made if we actually want to strive for a substantially more just society.
\end{abstract}

KEYWORDS: justice, egalitarianism, fairness, democracy.

RESUMO: Este artigo intenta ilustrar, ao focar em um elemento central da concepção igualitária forte de Rawls, a saber, a delineação de estruturas institucionais das sociedades em harmonia com o que é requerido pela justiça como equidade, o seguinte argumento: que sua teoria radical da justiça é ainda, e na verdade ainda mais, relevante para nossa situação atual. Em suma, as ideias de Rawls sobre o valor moral igual de pessoas livres e iguais, sobre "moral e mercados", sobre o fortalecimento e as questões de acesso ao processo político para cada um e para todos os cidadãos, sobre a "democracia deliberativa", sobre a "cidadania democrática", sobre o "dever de civilidade pública", sobre a "amizade cívica",

\footnotetext{
${ }^{1}$ Este artigo se utiliza de partes do livro LEHNING, P. B. John Rawls: An Introduction. Cambridge: Cambridge University Press, 2009. Em especial, faz uso daquelas partes que debatem a questão da justiça como equidade e o desenho das instituições. Neste artigo, bem como no livro que leva em consideração o trabalho integral de Rawls, não estou comprometido com 'o que eu mesmo penso que Rawls deveria ter dito, mas preferencialmente com o que Rawls disse, apoiado pelo que vejo como a mais razoável interpretação de seus textos' (LEHNING, 2009: xi).Tradução de Carlos Adriano Ferraz e Denis Coitinho Silveira.
} 
sobre o defeito básico do utilitarismo, sobre as desigualdades sociais e econômicas, nos mostram escolhas que podem ser feitas se realmente queremos alcançar uma sociedade substancialmente mais justa.

PALAVRAS-CHAVE: justiça, igualitarismo, equidade, democracia.

\section{INTRODUÇÃO}

Após vinte anos de trabalho, John Rawls (1921-2002) publicou, no final de 1971, sua principal obra, A Theory of Justice. Ela é reconhecida como uma das maiores obras de filosofia moral e política de todos os tempos. De fato, desde sua publicação em 1951 até seus últimos escritos, cerca de cinquenta anos depois, Rawls ocupou seu tempo tentando apresentar sua teoria da justiça como equidade (justice as fairness) de uma forma mais convincente.

Hoje, cerca de quarenta anos após a publicação de $A$ Theory of Justice, sua teoria radical de justiça é ainda mais relevante para nossa situação atual. As ideias de Rawls sobre o valor moral igual de pessoas livres e iguais, sobre 'moral e mercados', sobre as capacidades e questões de acesso ao processo político para cada e todo cidadão, sobre 'democracia deliberativa', sobre 'cidadania democrática', sobre 'o dever de civilidade pública', sobre 'amizade cívica', sobre o defeito básico do utilitarismo, sobre as desigualdades políticas, sociais e econômicas, mostram-nos as escolhas a serem feitas se realmente quisermos lutar por uma sociedade substancialmente mais justa. No que segue, ilustraremos isto focando sobre um elemento central da concepção de justiça igualitarista de Rawls: a forma das estruturas institucionais das sociedades em paralelo com o que é exigido pela justiça como equidade (justice as fairness).

\section{Justiça como Equidade}

\section{Os objetivos de Rawls}

O projeto integral de Rawls foi o de apresentar uma teoria da justiça que estabelece uma concepção política-filosófica razoável e prática para uma sociedade democrática constitucional justa, uma concepção que, ao mesmo tempo, fornece uma alternativa suficientemente sistemática ao utilitarismo. 
A posição de Rawls é que é nossa responsabilidade explorar a possibilidade - existindo as circunstâncias que permitem - de um mundo social justo em que formas permissíveis de vida tenham uma oportunidade equitativa para se manter e obter adeptos ao longo das gerações (PL: 198; JaF: $155)^{2}$. E Rawls está convencido que uma sociedade liberal justa é aquela que é mais adequada do que outros mundos sociais. É por esta razão que ele explora como as instituições políticas, sociais e econômicas básicas de uma democracia constitucional moderna deveriam ser concebidas de tal forma que, ao mesmo tempo, as liberdades de cada pessoa, bem como as reivindicações de igualdade democrática podem ser honradas. Seu primeiro objetivo é, então, apresentar uma resposta a esta questão.

Seu segundo objetivo é estabelecer uma concepção de justiça que represente uma alternativa razoável e sistemática ao utilitarismo em geral (pensamento que encontra sua inspiração em Jeremy Bentham (1748-1832) e John Stuart Mill (1806-1873) e, assim, representar uma alternativa para todas as suas diferentes versões que certamente tem dominado em círculos acadêmicos e, particularmente, a tradição de pensamento político anglo-saxã (sendo este o caso ao tempo da publicação de $A$ Theory of Justice em 1971).

O defeito básico do utilitarismo - sob qualquer de suas formas - é que os direitos básicos dos indivíduos podem ser sacrificados por um objetivo coletivo da sociedade, tal como a maximização do bem-estar social. Isto permite uma compensação inaceitável entre as pessoas: o utilitarismo formula um princípio que pode exigir uma menor perspectiva de vida para alguns simplesmente por causa de uma maior soma de vantagens desfrutadas por outros. O utilitarismo não reconhece que todos têm valor moral igual (o que, como veremos, para Rawls não implica que as parcelas distributivas tenham que ser iguais) e, portanto, não reconhece a forma como as pessoas são iguais umas as outras, nem a forma como elas diferem entre si. Ou, como

\footnotetext{
2 As seguintes abreviações das obras de Rawls são usadas neste artigo: CP: Collected Papers. Cambridge, MA: Harvard University Press, 1999; JaF: Justice as Fairness: A Restatement. Cambridge, MA: Harvard University Press, 2001; LHMP: Lectures on the History of Moral Philosophy. Cambridge, MA: Harvard University Press, 2000; LoP : The Law of Peoples. Cambridge, MA: Harvard University Press, 1999; PL: Political Liberalism. New York: Columbia University Press, 1996; TJ: A Theory of Justice. Cambridge, MA: Harvard University Press, 1971; TJR: A Theory of Justice. Revised Edition. Cambridge, MA: Harvard University Press, 1999. 'The Idea of Public Reason Revisited' é citado neste artigo como publicado em The Law of Peoples, p. 129-180. Então, LoP: 129-180 se refere a 'The Idea of Public Reason Revisited'.
} 
Rawls resumiu suas objeções contra o utilitarismo: "O utilitarismo não leva a sério a distinção entre as pessoas” (TJ: 27; TJR: 24).

Para Rawls, a ideia de valor moral igual de pessoas livres e iguais é básica: isto é a igualdade entre seres humanos como pessoas morais. Uma concepção de justiça deve refletir esta ideia de igualdade fundamental, expressando publicamente o respeito dos homens uns pelos outros. Ou, seguindo a concepção de Kant e colocando isto de outra forma, dizendo que a forma com que a sociedade é ordenada deve manifestar o desejo dos homens em tratar uns e outros não apenas como meios, mas como fins em si mesmos (TJ: 179; TJR: 156).

Como na visão kantiana, a concepção de justiça de Rawls aceita esta concepção de pessoa e, consequentemente, que pessoas morais livres e iguais têm diferentes concepções de bem em oposição. Esta concepção de justiça é independente e anterior à noção de bondade, no sentido em que seus princípios limitam as concepções de bem que são admissíveis em uma sociedade justa: eles devem ser coerentes internamente a estrutura desta concepção de justiça. Mencionamos que Rawls está convencido de que uma sociedade liberal justa é aquela mais adequada do que outros mundos sociais, isto é, que possui internamente espaço suficiente para várias formas de vida, para várias concepções de bem totalmente dignas de devoção. Mas estas concepções de bem devem ser coerentes com os limites desenhados pela concepção do justo em si mesma - pelo espaço que ela permite para perseguição dos bens permissíveis. Resumindo estas ideias em uma frase de Rawls: "o justo desenha (estabelece) o limite; o bem mostra o ponto" (LHMP. 231; JaF: 141). Esta prioridade do justo sobre o bem na concepção de justiça de Rawls, justiça como equidade, acaba por ser uma característica central desta concepção ${ }^{3}$.

O ponto de partida kantiano de Rawls- os homens desejam tratar os outros não apenas como meios, mas como fins em si mesmos - determina sua perspectiva sobre a sociedade ${ }^{4}$. Isto é, são as principais instituições da

\footnotetext{
${ }^{3}$ Assim como é, é claro, na ética de Kant. Ver para análise de Rawls sobre a ideia kantiana de prioridade do justo (right), LHMP : 217-234. Esta é parte da ampla análise a respeito de Kant: LHMP: 143-324.

${ }^{4}$ Rawls geralmente usa, em $A$ Theory of Justice, o termo 'interpretação kantiana'. Ver em TJ e TJR todo o § 40 sob o título 'A Interpretação Kantiana'. Para Rawls, existe analogia, não identidade, entre suas ideias e as de Kant. Para sublinhar isso ele adicionou em TJR, por exemplo, no final desse parágrafo, que "a interpretação kantiana não é tomada como uma interpretação da doutrina real de Kant, mas preferencialmente da justiça como equidade" (TJR: 226). E, posteriormente, Rawls explicitamente estipula no caso onde justiça como equidade é vista como política, não metafísica, "o adjetivo 'kantiano'
} 
sociedade, tomadas em conjunto como um esquema, que definem os direitos e deveres dos homens e influenciam seus projetos de vida; o que eles podem esperar ser e o que eles podem desejar fazer. Por principais instituições, Rawls entende a constituição (política) e as principais instituições econômicas e sociais: a estrutura básica da sociedade.

O foco de Rawls é quase inteiramente sobre a estrutura básica como o objeto da justiça social. Para ele a estrutura básica é o primeiro objeto dos princípios de justiça, da justiça como equidade porque seus efeitos sob as expectativas dos homens são difundidos e presentes a partir do início da vida (TJ: 54; TJR: 47). Este é o limite interno desta estrutura básica: que pessoas trabalham em conjunto: fazendo isto, por cooperação social, uma vida melhor para todos é possível. A sociedade deveria ser vista como um empreendimento cooperativo para vantagem mútua entre seres humanos racionais e razoáveis (TJ: 4 ; TJR: 4$)^{5}$.

O objetivo da teoria da justiça de Rawls é especificar quais são os termos equitativos da cooperação social. A forma com que esta cooperação social é organizada define a distribuição apropriada dos benefícios e encargos da cooperação social. A questão crucial, evidentemente, é o que é a 'distribuição apropriada de benefícios e encargos'. A resposta é dada pelos princípios de justiça social.

\section{Os princípios de justiça social}

O objetivo central de Rawls é determinar qual o conjunto de princípios que pessoas livres e iguais assentiriam para resolver o problema da distribuição. É por um método específico de justificação pública que estes

indica analogia, não identidade, isto é, semelhança de sentido suficiente em que o adjetivo é apropriado" (CP: 388: nota2).

${ }^{5}$ A ideia de Rawls é que a cooperação social produz bens primários. São estes bens primários que permitem pessoas livres e iguais perseguirem suas diferentes (e talvez opostas) concepções de bem. Rawls nos fornece a seguine lista destes bens primários: (a) liberdades básicas como dadas por uma lista, por exemplo: liberdade de pensamento e liberdade de consciência; liberdade de associação; e a liberdade definida pela liberdade e integridade da pessoa, bem como pelo estado de direito; e finalmente as liberdades políticas; (b) liberdade de movimento e escolha profissional contra uma pano de fundo de oportunidades diversas; (c) poderes e prerrogativas de cargos e posições de autoridade e responsabilidade, particularmente aquelas das principais instiutições políticas e econômicas; (d) renda e riqueza; (e) as bases sociais do autorrespeito. É a estrutura básica da sociedade que distribui estes bens primários sociais. O objetivo da teoria da justiça de Rawls é especificar como isto pode ser feito de uma maneira que seja equitativa. Para a enumeração dos bens primários, ver TJ: 62, 92; TJR: 54, 79; CP: 313-314, 362-363, 366; PL: 181; LoP: 13; JaF: 58-59. 
princípios são estabelecidos ${ }^{6}$. E, de acordo com Rawls, o resultado são os seguintes princípios que, tomados em conjunto como uma unidade, expressam a justiça como equidade. Eles definem a distribuição justa dos encargos e benefícios da cooperação social e atribuem direitos e deveres através da estrutura social integral ${ }^{7}$.

\section{O primeiro princípio:}

P 1: Cada pessoa deve ter um direito igual ao mais abrangente sistema total de liberdades básicas iguais que seja compatível com um sistema similar de liberdades para todos (the principle of equal liberty $)^{8}$.

O segundo princípio (que possui duas partes separadas):

P 2: As desigualdades sociais e econômicas devem ser ordenadas de tal modo que, ao mesmo tempo:

$P$ 2.1: sejam vinculadas a cargos e posições abertos a todos em condições de igualdade equitativa de oportunidades (o princípio de igualdade equitativa de oportunidade);

P 2.2: tragam o maior benefício possível para os menos favorecidos, obedecendo às restrições do princípio da poupança justa (o princípio da diferença) $)^{9}$.

As objeções que Rawls possui contra o utilitarismo são expressas não apenas nos próprios princípios da justiça, mas, também, no fato de que estes princípios têm prioridade em relação ao princípio da eficiência que maximiza a soma de vantagens ${ }^{10}$. Os princípios de justiça e sua ordem serial

\footnotetext{
${ }^{6}$ Para análise deste método de justificação, ver Percy B. Lehning. John Rawls: An Introduction. Cambridge: Cambridge University Press, 2009, p. 27-37; 121-125.

${ }^{7}$ Para a formulação dos princípios de justiça, ver TJ: 60, 250, 302; TJR: 53, 220, 266.

8 TJ: 250, 302; TJR: 220, 266. De 1982 em diante, Rawls não usou mais a formulação 'ao mais abrangente' no primeiro princípio de justiça, mas 'um esquema adequado integral.' Esta mudança foi feita por Rawls em reação a crítica formulada por H.L.A. Hart em 1973, em um importante artigo, 'Rawls on Liberty and its Priority', University of Chicago Law Review, 40(3): 534-555. Para a reação de Rawls, ver 'The Basic Liberties and Their Priority,' em Sterling M. McMurrin, ed., Tanner Lectures on Human Values, volume III, 3-87, Salt Lake City: University of Utah Press, 1982, e em uma versão revisada que é parte de $P L:$ 289-371. Para o princípio, ver $P L: 5,291$; ver, também, JaF: 42, 111-112.

${ }^{9}$ TJ: 302; TJR: 266; CP: 362, 392; JaF: 42-43; PL: 6.

10 Para regras de prioridade, ver, TJ: 302-303; TJR: 266-267. O termo correto é 'uma ordem lexicográfica", mas como o próprio Rawls observa, isto não é muito elegante. Ele usa 'lexical' ou 'serial', TJ: 42-43; TJR: 3738. Nós faremos o mesmo.
} 
nos permitem retratar mais claramente como os princípios de justiça se harmonizam conjuntamente:

O primeiro princípio de justiça tem prioridade sobre o segundo. Todas as pessoas têm garantidas as liberdades básicas iguais. As liberdades possuem, sob todas as circunstâncias, prioridade.

A primeira parte do segundo princípio tem prioridade sobre a segunda parte do segundo princípio de tal forma que a condição de igualdade equitativa de oportunidade é garantida igualmente para todos. Esta ideia de igualdade equitativa de oportunidade não deve ser confundida com a noção familiar de 'carreiras abertas aos talentos': o requisito de uma igualdade de oportunidade formal de maneira que todos tenham ao menos os mesmos direitos legais de acesso para todas as posições sociais vantajosas. O princípio é mais amplo por adicionar uma condição posterior que requer que posições não apenas estejam abertas em um sentido formal, mas que todos deveriam ter uma chance equitativa de obtê-las. Aqueles que possuem o mesmo nível de talento e habilidade, e possuem a mesma disposição para usá-los, deveriam ter a mesma expectativa de sucesso sem levar em conta seu lugar inicial no sistema social, sem levar em conta sua posição social. Por exemplo, no que diz respeito à educação, a sociedade deveria estabelecer, entre outras coisas, igualdade equitativa de oportunidades para todos sem levar em conta a renda familiar ${ }^{11}$.

Sujeita à restrição de assegurar cargos e posições de autoridade e responsabilidade abertos, as desigualdades em renda e riqueza devem ser arranjadas para o maior benefício dos menos favorecidos. Dada a prioridade do primeiro princípio sobre o segundo princípio, e dada a prioridade da primeira parte do segundo princípio sobre a segunda parte deste princípio, todas as pessoas em uma sociedade bem-ordenada têm as mesmas liberdades básicas iguais e igualdade equitativa de oportunidade.

\section{Justiça como equidade e desigualdades}

Justiça como equidade foca sobre as desigualdades nas perspectivas de vida das pessoas na medida em que estas são determinadas por três tipos principais de contingências: vantagens naturais, isto é, talentos e habilidades

\footnotetext{
11 Mas é precisamente 0 fato de que tantos fatores influenciam a motivação para estimular 0 desenvolvimento dos dotes naturais tais como posição social, a situação da família, circunstâncias sociais, torna muito dificil julgar se uma situação de igualdade equitativa de oportunidade foi alcançada. Rawls até pensa que alcançá-la na prática pode revelar-se impossível; ver TJ: 73, 301, 511; TJR: 73, 265, 448; JaF: 43-44.
} 
naturais, capacidades naturais - como estas têm sido desenvolvidas ou não realizadas, seu uso favorecido ou desfavorecido ao longo do tempo por circunstâncias sociais, que é sua classe social de origem, e por contingências de acaso como acidente e boa sorte, ou boa ou má sorte (saúde, desemprego involuntário). Cada uma destas três contingências influencia fortemente a possibilidade de cada pessoa realizar a sua concepção de bem. O objetivo de uma ordem social justa é um sistema de cooperação social que leve em conta os efeitos destas contingências (a distribuição arbitrária de capacidades naturais, as contingências das circunstâncias sociais, as contingências de acaso tal como acidente e boa sorte).

A sorte na distribuição de vantagens naturais e habilidades de alguém, sua inteligência, força etc., estes recursos internos, são o resultado da loteria natural. A distribuição das vantagens naturais não é justa ou injusta: ela é dada naturalmente. Ela é arbitrária de uma perspectiva moral e, consequentemente, vantagens naturais não são mérito moral de alguém. A forte convicção de Rawls é que as parcelas distributivas que são impropriamente influenciadas por estas contingências naturais, que são arbitrárias de um ponto de vista moral, não deveriam determinar as expectativas de vida que as pessoas possuem. Os princípios da justiça como equidade que regulam a estrutura básica e especificam os deveres e obrigações dos indivíduos não mencionam mérito moral, e não existe a tendência para as parcelas distributivas corresponderem a isto: expectativas legítimas não devem ser baseadas sobre o mérito moral.

Há também o problema fundamental que as expectativas e possibilidades na vida sejam fortemente influenciadas pelas contingências sociais, pela posição social que cada um nasceu: um lugar na estrutura política, econômica ou social das instituições básicas da sociedade. Isto não tem nada a ver com mérito: não é 'justo' ou 'injusto' que pessoas nasçam na sociedade em alguma posição particular. Isto é, de acordo com Rawls, um dos pontos fixos de nossos juízos morais: que ninguém merece seu ponto de partida inicial na sociedade, da mesma forma que ninguém merece seu lugar na distribuição das vantagens naturais. Isto introduz um grau elevado de sorte na vida das pessoas, mas é a sorte que é influenciada pelas instituições da sociedade. O que é justo e injusto é a forma das instituições lidarem com estas contingências naturais e sociais.

Alcançamos aqui uma ideia fundamental da teoria da justiça de Rawls, se não for a sua ideia básica. Esta é sua "noção intuitiva (...) que a estrutura básica controla várias posições sociais e que os homens nascem em diferentes posições que possuem diferentes expectativas de vida que são 
determinadas, em parte, pelo sistema político, bem como pelas circunstâncias econômicas e sociais. Desta forma, as instituições da sociedade favorecem certos pontos de partida sobre outros. Estas são especialmente desigualdades profundas. Não apenas elas são difundidas, mas elas afetam as chances iniciais na vida dos homens; elas ainda possivelmente não podem ser justificadas por um apelo às noções de mérito ou merecimento. São sobre estas desigualdades, presumivelmente inevitáveis na estrutura básica de qualquer sociedade, que os princípios de justiça social devem ser aplicados em primeira instância. Estes princípios, então, regulam a escolha de uma constituição política e os principais elementos do sistema econômico e social”. (TJ: 7; TJR: 7; ênfase acrescida)

O caráter radical da teoria de Rawls recai no fato de que ela enfoca sobre a virtude destas instituições básicas. Nascer como um filho de escravos ou de proprietários de escravos, ou como um filho de um trabalhador não qualificado ou como um filho de um membro da classe empresarial é puramente arbitrário. Em todas as instâncias, é puramente arbitrária as circunstâncias sociais em que se nasce. Entretanto, as instituições que permitem a escravidão ou o capitalismo são criadas pelos homens. A questão relevante, então, não é se um dono de escravos está agindo de forma 'justa' ou 'injusta' no sentido de ser um 'bom' ou 'mau' ser humano. O problema aqui, preferencialmente, é que a instituição 'escravidão' não possui 'virtude' e é injusta.

A teoria de Rawls formula um projeto institucional. É por isto que ele pode iniciar Uma Teoria da Justiça da seguinte forma: "A justiça é a primeira virtude das instituições sociais, assim como a verdade o é dos sistemas de pensamento. Uma teoria mesmo que elegante e econômica deve ser rejeitada ou revisada se não for verdadeira; da mesma forma que leis e instituições mesmo que eficientes e bem arranjadas devem ser reformadas ou abolidas se forem injustas. (...) Sendo as primeiras virtudes de atividades humanas, verdade e justiça são inflexíveis” (TJ: 3-4; TJR: 3-4).

A questão básica que Rawls deseja que consideremos é se estamos realmente interessados em levar em conta as desigualdades não desejadas no desenho institucional de nossa sociedade: estas desigualdades que são arbitrárias de um ponto de vista moral. A ideia guia deve ser que o fato de que seres humanos deveriam ser determinados pelas escolhas livres que eles fazem quando questões de como eles desejam organizar suas vidas chegam. Não é equitativo que estas escolhas sejam determinadas por diferenças 
arbitrárias e imerecidas em circunstâncias sociais e nem que sejam determinadas por diferenças em vantagens naturais que são dadas aos seres humanos 'por natureza'. Ninguém merece sua maior capacidade natural nem merece um lugar inicial mais favorável na sociedade: desigualdades de nascimento e capacidades naturais são imerecidas. Direitos morais não podem estar baseados sobre a sorte na loteria natural ou sobre a sorte social; elas não devem influenciar nos benefícios e encargos da cooperação social compartilhados pelos homens.

Agora isto pode ser o caso que o que é justo e injusto é a forma em que as instituições lidam com as contingências naturais e sociais, mas disto não implica que as próprias instituições sejam um fato natural, ou 'um dado natural'. As instituições não são inalteráveis e não estão além do controle humano. Ao contrário, a ordem da estrutura básica da sociedade é 'feita pelo homem' e é modificável. A questão é então: como devem ser designadas as instituições políticas, sociais e econômicas básicas de uma democracia constitucional moderna de forma que, ao mesmo tempo, as liberdades básicas de cada pessoa, bem como as reivindicações de igualdade democrática, em que o princípio da diferença está encravado podem ser honradas?

\section{Instituições e igualdade democrática}

\section{Instituições de fundo equitativo e arranjos de mercado}

Iniciando com o problema da desigualdade social e econômica, as questões são: como garantir a realização da melhor forma possível dos princípios de justiça como equidade no que se refere às parcelas distributivas? Qual seria a forma apropriada de instituições econômicas de fundo para regular a atividade econômica? Quais sistemas econômicos seriam consistentes com as liberdades iguais e a igualdade equitativa de oportunidade, bem como com os requisitos de parcelas distributivas equitativas?

O esboço de Rawls do esquema de instituições econômicas básicas faz uso de um sistema de mercados que funcionam de tal forma que o resultado do processo econômico é justo bem como é eficiente. Isto não é surpreendente se se considerar que a teoria de um mercado econômico perfeitamente competitivo é um procedimento perfeito que sempre levará a um resultado eficiente. Rawls assegura que apenas usando um sistema de 
mercados o problema da distribuição justa pode ser tratado como um caso de justiça procedimental pura. Não existe critério independente para julgar se o resultado é o resultado correto. Existe um procedimento equitativo ou correto que garante que o resultado é equitativo ou correto seja lá o que aconteça (providenciando, é claro, que o procedimento foi propriamente seguido). As circunstâncias de fundo definem um procedimento equitativo. $\mathrm{E}$ um procedimento equitativo transfere esta equidade para o resultado. E uma economia competitiva adequadamente regulada com as instituições de fundo apropriadas é um esquema ideal para realizar a justiça procedimental pura. A distribuição será justa (ou ao menos não injusta) seja lá o que aconteça. Desse modo, Rawls faz a escolha por uma economia de mercado como ordem econômica em que a justiça como equidade tem que ser realizada (T): 274, 304, 309; TJR: 242, 268, 272).

Enquanto uma das vantagens de uma economia de mercado é a eficiência, isto não pode, é claro, ser a única razão para esta escolha: afinal, a justiça social tem prioridade sobre a eficiência. Esta escolha para arranjos de mercado também não está baseada na propriedade privada de instrumentos de produção a recursos naturais, argumentos que muitas vezes são usados como uma precondição de um 'mercado livre'. Não existe um elo essencial entre o uso de mercados livres e propriedade privada de instrumentos de produção. Embora seja verdadeiro que a alocação de instrumentos de produção e produtos por um mercado pressupõe um sistema de empresas (empresas tomadas como unidades de produção com decisão independente), isto não significa necessariamente que os meios de produção sejam apropriados privadamente. De fato, Rawls observa aqui a consistência dos arranjos de mercado com instituições socialistas: instituições de mercado são comuns aos regimes de propriedade privada e de socialismo liberaldemocrático. "Tanto faz a natureza das empresas, se elas são privadas ou estatais, ou se elas são dirigidas por empresários ou por gerentes eleitos pelos trabalhadores, elas tomam os preços de entradas e saídas como dadas e estabelecem seus planos de acordo" (TJ: 272; TJR: 241). Mesmo observando esta consistência de arranjos de mercado com as instituições socialistas se deve, entretanto, distinguir entre a função alocativa e a função distributiva de preços. "Desde que sob o socialismo os meios de produção e recursos naturais são possuídos publicamente, a função distributiva é largamente restringida, enquanto o sistema de propriedade privada usa os preços em graus variados para ambos os propósitos” (TJ: 273-274; TJR: 242). Em ambos 
os tipos de regimes, o sistema de mercado descentraliza o exercício do poder econômico. Também os sistemas de propriedade privada e socialista (liberaldemocrático) normalmente permitem a livre escolha de ocupação e o próprio lugar de trabalho. Não existe razão para a centralização forçada do trabalho ${ }^{12}$. É somente sob sistemas de comando de qualquer tipo que esta liberdade sofre abertamente interferência.

E aqui chegamos ao principal motivo da escolha de Rawls pelos arranjos de mercado: ele é de opinião que um sistema de mercado - ao contrário de uma economia centralizada - dá ao indivíduo o maior conjunto possível de liberdades. Uma vantagem significativa de um sistema de mercado é que, dadas as instituições de fundo requeridas, ele é consistente com as liberdades iguais e com a igualdade equitativa de oportunidade. E isto é importante para a realização daquela parte do princípio de igualdade equitativa de oportunidade que garante aos cidadãos uma escolha livre de profissões e ocupações (TJ: 274; TJR: 242; JaF: 67, 67 nota 35 ).

Em conclusão: um sistema de mercado (ideal) é consistente com as demandas do primeiro princípio de justiça, bem como com o princípio da igualdade equitativa de oportunidade. Mas a escolha de um sistema de mercado necessita de uma especificação adicional. Certamente esta escolha pode ser consistente com ambos os princípios, bem como com a eficiência, mas arranjos de mercado deixados por si mesmos não garantem resultados justos. Estes arranjos requerem instituições de fundo equitativas que continuamente ajustam e compensam suas tendências inevitáveis a partir de uma equidade de fundo que permanece consistente com as demandas do princípio da diferença (T): 272-275; TJR: 240-243; PL: 267).

Melhor detalhando: o papel das instituições que pertencem à estrutura básica é o de assegurar condições de fundo equitativas contra as quais as ações dos indivíduos e associações - que são partes da sociedade como um todo tomam lugar. Assim, a distribuição resultante de transações de mercado voluntárias (mesmo considerando todas as condições ideais para obter eficiência competitiva) não é, em geral, equitativa a menos que a distribuição antecedente de renda e riqueza, bem como a estrutura dos mercados, seja equitativa. A riqueza existente deve ter sido devidamente adquirida e todos

\footnotetext{
${ }^{12} \mathrm{Em}$ teoria, um regime socialista liberal também pode responer aos dois princípios de justiça. A teoria da justiça não favorece nenhuma forma de regime. A decisão de qual sistema é melhor para um dado povo depende de suas circunstâncias, instituições, e tradições históricas, e forças sociais de cada país. TJR: xV-xvi; TJ: § 42; TJR: § 42; JaF: 138-139.
} 
devem ter oportunidades equitativas para obter renda, para aprender as habilidades desejadas, e assim por diante (TJ: 359; TJR: 316; PL: 266).

Em adição, a menos que a estrutura básica seja devidamente regulada e ajustada, um processo social inicialmente justo eventualmente cessará de ser justo, entretanto transações particulares podem parecer livres e equitativas quando observadas em si mesmas. Portanto, mesmo baseada em um grande elemento de justiça procedimental pura na determinação das parcelas distributivas, uma concepção de justiça "deve incorporar uma forma ideal da estrutura básica à luz da qual os resultados acumulados de processos sociais em curso devem ser limitados e ajustados" (PL: 281; JaF: 161).

A justiça das parcelas distributivas depende das instituições de fundo e de como elas distribuem a renda total para os menos favorecidos (salários mais outras transferências de renda de tal forma que reivindicações de necessidade e um padrão apropriado de vida sejam alcançados), como requerido pela (aplicação do) princípio da diferença (TJ: 304, 277; TJR: 245, 267; JaF: 59).

Portanto, Rawls não afirma que todas as desigualdades em (renda) recompensas que são o resultado de trocas de mercado possam ser defendidas, fazendo um apelo para o efeito temido de incentivos negativos. Existe com razão uma forte objeção à determinação competitiva de renda total, uma vez que ela ignora as reivindicações de necessidade e um padrão apropriado de vida. Como o mercado não é adequado para responder a estas reivindicações de necessidade, estas devem ser encontradas por um arranjo separado. Portanto, as instituições de fundo também têm que implicar em medidas que assegurem contra essas contingências de mercado. De fato, o princípio a diferença, presumivelmente, exige isso. Mas uma vez que um mínimo adequado é fornecido através de transferências, pode ser perfeitamente equitativo que o restante da renda total seja estabelecido pelo sistema de preços, supondo que ele é moderadamente eficiente e livre de restrições monopolísticas, sendo eliminadas as externalidades não-razoáveis.

Instituições de apoio específicas são necessárias para isto. Assim, a estrutura básica também inclui estas operações que continuamente ajustam e compensam as tendências inevitáveis que estão afastadas da equidade de fundo. Exemplos aqui são tais operações como taxação sobre renda e herança, projetados para além da posse da propriedade (PL 268; JaF: 160-161).

Há mais uma suposição importante que Rawls acrescenta na elaboração deste esboço das instituições de fundo. Desde o início sua 
suposição é que o tipo de regime democrático é uma democracia de cidadãosproprietários (property-owning democracy). Neste regime os bens produtivos, "terra e capital são amplamente possuídos, embora, presumivelmente, não possuídos igualmente (TJ: 280; TJR: 247). (Os termos, bem como algumas características desta ideia são tomados de empréstimo por Rawls do economista James Meade $^{13}$ ). A suposição de Rawls é que com este esquema de instituições de fundo os princípios de justiça como equidade possam ser realizados.

Resumindo: Rawls está convencido que a liberdade da pessoa é melhor garantida em uma economia de mercado, se livres arranjos de mercado forem razoavelmente competitivos e abertos e se eles forem estabelecidos com um sistema de princípios que organizam as instituições de fundo de uma democracia constitucional, instituições que regulam as tendências globais de eventos econômicos e preservam as condições sociais necessárias para a igualdade equitativa de oportunidade. Se uma estrutura básica foi designada de acordo com isto, as parcelas distributivas serão justas (ou ao menos não injustas) seja lá o que elas sejam. O sistema permanece equitativo ao longo do tempo, de uma geração à outra (JaF: 51).

\section{Justiça como equidade e o "capitalismo de bem-estar social"}

Rawls contrasta uma "democracia de cidadãos-proprietários" (propertyowning democracy) com um estado de bem estar social, ou "capitalismo de bem-estar social” (welfare-state capitalism). Esta comparação ilustra que o ideal de Rawls acerca de uma sociedade política democrática estável, social e liberal coerente contém uma crítica fundamental à ideia de "capitalismo de bem-estar social”. Esse tipo de regime não satisfaz às demandas colocadas pela justiça como equidade ${ }^{14}$.

Para começar, permita-nos lembrar que, no esquema ideal das instituições de fundo de apoio ou "circundantes" da justiça como equidade, não apenas é feito um uso considerável de arranjos de mercado, mas Rawls

\footnotetext{
${ }^{13}$ Meade inicia seu quinto capítulo, 'Uma Democracia de Cidadãos-Proprietários', como segue: "Vamos supor que pelo efeito de alguma varinha mágica (...) a posse da propriedade seria igualmente distribuída para todos os cidadãos da comunidade"; J.E. Meade. Efficiency, Equality, and the Ownership of Property, 40, Cambridge, MA: Harvard University Press, 1965.

14 Ver, para um contraste entre "democracia de cidadãos-proprietários" e "capitalismo de bem-estar social", TJR: xiv-xV; JaF: 135; 138-140. Ver, para uma elaboração da distinção entre "democracia de cidadãos-proprietários" e um "capitalismo de bem estar social", Richard Krouse e Michael McPherson, 1988, 'Capitalism, 'property-owning democracy', and the welfare state,' em: A. Gutmann, ed., Democracy and the Welfare State, 79-105, Princeton: Princeton University Press.
} 
também assume que a espécie de regime é aquele de uma "democracia de cidadãos-proprietários”. O papel das instituições de fundo em uma "democracia de cidadãos-proprietários" é "a constante dispersão, ao longo do tempo, da propriedade de capital e recursos pelas leis da herança e do legado, baseada na equânime igualdade de oportunidade assegurada por provisões para educação e formação, e assim por diante, bem como em instituições que dão suporte ao valor justo das liberdades políticas” (TJR: xv). Assim, evita-se que uma pequena parcela da sociedade controle a economia e, indiretamente, também a vida política (TJR: xiv-xv; JaF: 139).

Agora, a primeira diferença importante entre "capitalismo de bem-estar social" e uma "democracia de cidadãos-proprietários" é que o "capitalismo de bem-estar social” permite que uma pequena classe tenha quase o monopólio dos meios de produção. Em segundo lugar, a principal preocupação, em um capitalismo de bem-estar social, é a busca pelo auto-interesse por cada cidadão, individual e separadamente. Isto teria, ou pelo menos assim segue a pretensão, um efeito positivo para cada um e para todos os membros da sociedade: o nível geral de riqueza na sociedade seria ampliado ou mesmo maximizado. Aqui a moralidade politica da utilidade reina, personificada pelo ethos competitivo do cidadão calculista, maximizando suas posses materiais. Trata-se de uma 'sociedade privada' em sentido amplo, uma sociedade "não unificada por uma convicção pública de que seus arranjos básicos são justos e bons por eles mesmos, mas pelos cálculos de todos, ou por muitos o suficiente para manter o esquema segundo o qual quaisquer mudanças praticáveis reduziriam o estoque de meios pelos quais eles perseguem seus fins pessoais" (TJ: 522; TJR: 458).

Voltando-nos para as provisões de bem-estar em um estado de bem-estar capitalista, deve-se notar que estas podem ser muito generosas e garantir um mínimo social decente, cobrindo necessidades básicas. Seja como for, o importante é focarmos no objetivo de um estado de bem-estar social. E este é o de que "ninguém deveria cair abaixo de um padrão decente de vida, e que todos deveriam receber certas proteções contra acidentes e infortúnios - por exemplo, cuidado médico e compensação por desemprego. A redistribuição de renda serve a este propósito quando, ao final de cada período, aqueles que necessitam de assistência podem ser identificados. Tal sistema pode permitir amplas e herdáveis desigualdades de riqueza incompatíveis com o valor equitativo das liberdades políticas (...), bem como amplas disparidades de renda que violam o princípio da diferença. Enquanto algum esforço é feito para assegurar a igualdade equitativa de oportunidades, este ou é insuficiente ou 
ineficaz, dadas as disparidades de riqueza e a influência política que estas disparidades permitem" (TJR: xv; JaF: 139-140; ênfase acrescida).

Esta concepção acerca do objetivo dos ajustes feitos pelas instituições de fundo ao longo do tempo é ilustrativa para os defeitos básicos do 'capitalismo de bem-estar social'. A questão não deveria ser, consoante Rawls, ajudar as pessoas uma vez que elas fossem atingidas por algum acidente ou infortúnio. Em virtude da ausência de uma justiça de fundo, e em virtude das desigualdades de renda e riqueza, "pode se desenvolver uma subclasse desencorajada e deprimida na qual muitos membros são cronicamente dependentes de assistência social. Esta subclasse sente-se deixada de lado e não participa da cultura política pública” (JaF: 140). Formulado de outra forma: 'capitalismo de bem-estar social' não reconhece uma ideia de reciprocidade que regule as desigualdades sociais e econômicas.

Agora compare isto com a 'democracia de cidadãos-proprietários'. Nesta "o objetivo é realizar a ideia de sociedade enquanto um sitema equitativo de cooperação ao longo do tempo entre cidadãos enquanto pessoas iguais e livres. Logo, instituições básicas devem, desde o início, pôr, nas mãos dos cidadãos em geral, e não de alguns poucos, os meios de produção suficientes para que eles sejam membros plenamente cooperadores de uma sociedade (em pé de igualdade)" (TJR: xv; JaF:140; ênfase acrescida). O propósito da 'democracia de cidadãos-proprietários' não é o de simplesmente dar assistência àqueles que saem perdendo em virtude de acidente ou infortúnio, mas, pelo contrário, trazer todos os cidadãos para uma posição na qual eles sejam capazes de administrar seus próprios assuntos em pé de adequado grau de igualdade social e econômica. A esperança de Rawls é que, sob estas condições, os menos afortunados também participem da cultura política pública. Nesta situação, alguém pode evitar que surja uma subclasse. Os menos favorecidos percebem que eles também 'pertencem à sociedade'. Eles não são, pois, os "desafortunados e azarados, - objetos de nossa caridade, compaixão, ou, muito menos, piedade - mas aqueles para os quais a reciprocidade é devida enquanto matéria de justiça política entre aqueles que são cidadãos livres e iguais como todos os demais" (JaF: 139).

Tendo contrastado estas duas espécies de regimes para ilustrar o que Rawls tem em mente como uma sociedade desenhada de acordo com os objetivos e princípios da justiça como equidade, devemos notar que, de fato, com respeito a isso, coisa alguma mudou ao longo dos anos, e que isto está em consonância total com o que Rawls afirmou em 1971 em Uma Teoria da 
Justiça ${ }^{15}$. A posição de Rawls permaneceu a mesma: o tipo de regime que melhor se harmoniza à justiça como equidade é, ainda, a 'democracia de cidadãos-proprietários'. Rawls estava convencido de que a estrutura básica de uma 'democracia de cidadãos-proprietários' realizará - tanto quanto possível a noção central da justiça como equidade: justiça procedimental pura de fundo, de uma geração à outra.

\section{Instituições e a cidadania democrática}

\section{0 ideal de razão pública, de liberdades políticas e de democracia deliberativa}

Charles Taylor descreveu a noção central de 'humanismo cívico' como aquele em que os 'homens encontram o bem na vida pública de uma república de cidadãos' (PL: 206). Tomando emprestada essa interpretação de humanismo cívico de Taylor, Rawls rejeita a visão que pretende que a participação seja o locus priviligiado de nosso bem (completo) (PL: 206; JaF: 142-143) ${ }^{16}$. Em uma sociedade democrática moderna, tomar parte contínua e ativamente da vida pública geralmente tem um lugar menor nas concepções de bem da maioria dos cidadãos. Isto não parece problemático, uma vez que cidadãos não são seres políticos cuja natureza essencial seja tal que eles podem apenas atingir seus planos de vida pela participação ampla e ativa na vida política.

Mas mesmo rejeitando uma visão tal qual a de humanismo cívico, "isto não significa um impedimento para colocarmos certas liberdades políticas entre as liberdades básicas e as protegermos a partir da prioridade da liberdade" (PL: 299). Elas são, por exemplo, importantes enquanto meios institucionais essenciais para garantir as outras liberdade básicas. A questão, então, é, em que medida, e de que maneira, engajar-se na vida política é necessário para a proteção das liberdades básicas: se formos permanecer cidadãos iguais e livres, não podemos, como cidadãos, arcar com um êxodo completo da vida política

\footnotetext{
${ }^{15}$ Não devemos, a esse respeito, ser distraídos pelas observações de Rawls no prefácio acrescentado à edição revisada de Uma Teoria da Justiça, nas quais ele discute, entre outras coisas, o contraste entre 'democracia de cidadãos-proprietários' e um 'estado de bem-estar social'. Todos os elementos para observar o contraste já estavam colocados muito antes em suas obras.

16 Ver, também, PL: 420-421. Rawls se refere, aqui, a Charles Taylor, Philosophy and the Human Sciences. Philosophical Papers 2.335, Cambridge: Cambridge University Press, 1985; ver também PL: 206 nota 38; JaF: 142 nota 8.
} 
para a vida privada. Isso poderia conduzir a uma perda da liberdade de todos. A segurança das liberdades democráticas, incluindo as liberdades da vida nãopolítica, requer a participação ativa de cidadãos que possuam as virtudes políticas necessárias para sustentar um regime constitucional (PL: 205; CP. 469; JaF: 144).

Vemos, aqui, a importância e a necessidade do papel educativo de uma concepção política de justiça. As instituições básicas de uma sociedade bemordenada devem educar os cidadãos para que estes vejam a si mesmos como livres e iguais. A concepção política pública de justiça formula não apenas os princípios para o ordenamento das instituições básicas da sociedade, mas também seu papel educativo mais amplo. Neste papel elas são parte da cultura política pública. Apontando, por exemplo, para o debate político público mediante o qual os cidadãos se familiarizam com seus direitos e deveres básicos e com as razões pelas quais estes devem ser respeitados, podemos tipificá-la como 'republicanismo cívico' (JaF: 146) ${ }^{17}$.

As questões levantadas, aqui, estão intimamente relacionadas com a realização do "ideal de razão pública”. Este ideal caracteriza a relação política democrática mesma: o dever de adotar uma certa forma de discurso público, uma concepção de cidadania democrática e de exercício conjunto de cidadãos com derradeiro poder político. Os valores da razão pública, os quais governam o debate político, referem-se aos direitos e liberdades básicas de cidadania que devem ser respeitadas pelas maiorias legislativas. Elas referem-se mais especificamente ao direito a voto, a participar da política, à liberdade de consciência, de pensamento e de associação, bem como à proteção do estado de direito.

Os valores da razão pública refletem nossa disposição enquanto cidadãos de tentar resolver questões políticas fundamentais de tal forma que outros cidadãos como livres e iguais podem reconhecer como razoáveis e racionais. Em seu núcleo está 'o dever de civilidade pública', um dever moral, e não legal, pelo qual os cidadãos vêem-se obrigados a um uso público da razão ao discutirem publicamente questões fundamentais de justiça (PL: 217-218; JaF: 92, 117; LoP. 55-56, 155). De fato, 'o critério de reciprocidade' é o que o ideal de razão pública provoca. O papel (o critério) da reciprocidade, tal como expresso na razão pública, é especificar a natureza da relação política em um

${ }^{17}$ Rawls refere-se, quanto ao uso dessa terminologia, a Cass Sunstein, 1988, 'Beyond the Republican Revival', Yale Law Journal, 97: 1539-1590; ver, também JaF: 146 note 16. 
regime democrático constitucional como uma 'amizade cívica' (PL: xliv, li, 4850, 226; LoP. 35, 136-137, 155) $)^{18}$.

O ideal de razão pública enfatiza a importância da 'democracia deliberativa'. A ideia definitiva de democracia deliberativa é a deliberação ela mesma. Ela é uma ordem política e social na qual a justificação dos termos de associação avançam pela razão pública, e na qual um sistema ideal de deliberação é refletido nas instituições sociais e políticas (PL: 430; JaF: 148; LoP. 137-139). 'Democracia' não é uma negociação baseada em auto-interesse e em comportamento estratégico. Ela não se identifica com a ideia de cidadão como homo economicus, o qual vê na política um único aspecto: meios de levar vantagem. Democracia defende a necessidade de deliberação e de um debate público; ela "limita as razões que os cidadãos podem dar em suporte de suas opiniões políticas a uma razão consistente com a visão dos outros cidadãos como iguais" (LoP. 139 nota 21).

Há, todavia, uma condição necessária a ser acrescentada a essas exigências da democracia deliberativa, para preparar o palco para o exercício da razão pública: o valor equitativo das liberdades políticas (de discurso, de reunião, de voto).

\section{0 valor equitativo das liberdades políticas e 0 acesso ao processo político}

Que a segurança das liberdades democráticas requer a participação ativa dos cidadãos, como observado acima, significa que os direitos ao voto, à participação na política e a iguais liberdades políticas, estão ligadas às questões de acesso ao processo político. Esta não é apenas uma questão formal, mas também substantiva. É bem conhecido que as desigualdades sociais e econômicas podem ser tais que elas impedem os cidadãos de exercerem suas liberdades políticas formais. Em Uma Teoria da Justiça, Rawls já havia notado que é o valor equitativo das liberdades políticas que permite que os cidadãos participem em pé de igualdade da vida pública/política. O valor das liberdades políticas, seja qual for a posição social e econômica dos cidadãos, deve ser aproximadamente igual, ou, ao menos, suficientemente igual, no sentido de que todos tenham uma oportunidade equânime para ocupar cargos públicos e para ter influência sobre a tomada de decisões políticas. Todos os cidadãos

\footnotetext{
18 Observe que a ideia de amizade cívica não é nova. Em Uma Teoria da Justiça esta ideia estava ligada à ideia de fraternidade. A ideia de fraternidade era, por sua vez, expressa pelo princípio da diferença; e o princípio da diferença expressa a ideia de reciprocidade.
} 
devem, portanto, ter uma chance equitativa para acrescentar propostas alternativas à agenda da discussão política. A concepção de 'valor equitativo' (fair-value) foi introduzida para responder à objeção de que as liberdades iguais nas democracias modernas são, na prática, meramente formais. Rawls observa que as "liberdades protegidas pelo princípio da participação perdem muito de seu valor quando se permite que aqueles que têm os maiores meios privados usem de suas vantagens para controlar o curso do debate público. Pois eventualmente estas desigualdades irão permitir que os bem situados exerçam uma abrangente influência sobre o desenvolvimento da legislação. No devido momento eles irão, provavelmente, adquirir um peso preponderante na resolução de questões sociais, pelo menos no que diz respeito àquelas questões acerca das quais eles normalmente concordam, o que significa dizer, àquelas coisas que dão suporte às suas circunstâncias preferidas" (TJ: 225; TJR: 198) $)^{19}$.

É o banimento das desigualdades da influência política que surgem dos recursos desiguais que conduz à exigência deste valor equitativo. $\mathrm{O}$ valor equitativo das liberdades políticas exige instituições bem concebidas. Ele necessita de uma situação na qual as instituições de fundo para a implementação da justiça distributiva evitem o acúmulo excessivo de propriedade e riqueza (TJ: 225, 278; TJR: 197-198, 245). De fato, uma das condições que garantem o 'valor equitativo' das liberdades políticas é que "propriedade e riqueza devem ser amplamente distribuídas e verbas governamentais devem ser regularmente disponibilizadas para encorajar a discussão pública livre” (TJ: 225; TJR: 198).

Em adição, medidas devem ser tomadas com vistas a garantir que partidos políticos sejam independentes de interesses privados, de grandes concentrações de poder privado enconômico e social, e isso concedendo-lhes suficiente renda oriunda de impostos, para que eles possam desempenhar sua parte no esquema constitucional; que haja um financiamento público para campanhas políticas e despesas de eleição; que hajam restrições a contribuições para campanhas; que haja formas de assegurar a disponibilidade de informações públicas sobre questões políticas; que seja assegurado um maior acesso à mídia pública ${ }^{20}$. Em resumo, como Rawls posteriormente o formulou, “a deliberação pública deve (ser) livre da maldição do dinheiro" (LoP. 139).

\footnotetext{
19 Ver, também, JaF: 148.

20 Esta é uma questão que exige constante atenção e preocupação. A maldição do dinheiro nos assuntos políticos é uma questão levantada em muitas publicações de Rawls; ver, por exemplo, TJ: 225228; TJR: 197-200; PL: Iviii, 328, 357; LoP: 24 nota 19; 50; 139; JaF: 149-150.
} 
Em O Liberalismo Político, Rawls repete estes argumentos sobre o valor equitativo das liberdades políticas. Novamente, sua garantia é uma forma pela qual o liberalismo político tenta confrontar a objeção de que as liberdades políticas são meramente formais. Ele permite que os cidadãos participem da vida política pública. Esta garantia do valor equitativo das liberdades políticas tem vários aspectos dignos de nota. Primeiramente, ela "assegura para cada cidadão um equitativo e aproximadamente igual acesso ao uso da habilidade pública .... a qual governa o processo político e controla a entrada em posições de autoridade política”. Em segundo lugar, "esta habilidade pública tem um espaço limitado, por assim dizer. Consequentemente, na ausência da garantia do valor equitativo das liberdades políticas, aqueles com relativamente grandes meios podem unir-se e excluir aqueles que possuem menos" $(P L: 328)^{21}$.

$\mathrm{E}$, novamente, garantir que as liberdades políticas sejam asseguradas em virtude de seu valor equitativo, bem como assegurar o acesso igual ao processo político, significa que o valor das liberdades políticas de todos os cidadãos, seja qual for sua posição social e econômica, deve ser aproximadamente igual, ou, ao menos, suficientemente igual. Como ele observa, "garantir o valor equitativo das liberdades políticas é de igual, senão de maior importância, do que garantir que os mercados sejam funcionalmente competitivos. Pois a menos que o valor equitativo dessas liberdades seja aproximadamente preservado, instituições de fundo justas dificilmente serão estabelecidas ou mantidas" (PL: 327-328). De fato, o valor equitativo das liberdades políticas tornou-se uma parte integral do primeiro princípio de justiça. O primeiro princípio agora pode ser lido: "cada pessoa tem uma reivindicação igual a um esquema totalmente adequado a direitos e liberdades básicas, esquema este compatível com o mesmo esquema para todos; e neste esquema as liberdades políticas iguais, e somente estas liberdades, serão garantidas pelo seu valor equitativo" ( $P L: 5)$.

Agora, alguém poderia bem argumentar que a condição necessária para o 'valor equitativo' das liberdades políticas ('propriedade e riqueza devem ser amplamente distribuídas') é cuidada na ideia de justiça como equidade. Parece haver, afinal de contas, um princípio colocado para garanti-lo: o princípio da diferença. Mas verifica-se que, em Uma Teoria da Justiça, e, posteriormente, em O Liberalismo Político, na verdade até Justiça como Equidade: Uma Reformulação, Rawls é da mesma opinião: o princípio da diferença não é suficiente para garantir que "propriedade e riqueza sejam amplamente

${ }^{21}$ Ver, também, JaF: 150. 
distribuídas". "Não podemos ter certeza”, Rawls afirma, "que as desigualdades permitidas pelo princípio da diferença serão suficientemente pequenas para prevenir isto", e, portanto, mesmo com o princípio da diferença em seu lugar, aqueles com menos meios continuam impedidos de ter acesso equitativo e igual ao processo político enquanto habilidade pública (PL: 328; JaF: 150). Formulado de outra forma: a garantia do valor equitativo das liberdades políticas requer restrições mais fortes sobre as desigualdades do que o princípio da diferença poderia permitir. O princípio da diferença é presumivelmente insuficiente para prevenir aqueles com maiores meios de unirem-se e excluírem os que possuem menos. Logo, medidas adicionais são necessárias para garantir o valor equitativo das liberdades. E Rawls menciona aqui, por exemplo, o progressivo princípio de taxação para prevenir o acúmulo de riqueza ajuizado como hostil para a justiça de fundo, tal como para o valor equitativo das liberdades políticas (TJ: 277; TJR: 245; JaF: 161).

Mas são, não obstante, argumentos relacionados às questões de acesso ao processo político, bem como argumentos para a possibilidade real de usar tais liberdades e oportunidades, que limitam, de formas importantes, o nível aceitável de desigualdades. Mas há mais argumentos a serem dados que colocam limites sobre o que é um nível aceitável de desigualdades.

Já fizemos notar (ao discutirmos a 'democracia deliberativa') que o ideal de razão pública implica uma forma de deliberação pública, e que uma crença na importância da deliberação pública é essencial a um regime constitucional razoável. $\mathrm{O}$ argumento segundo o qual um processo político equitativo deveria ser aberto a todos em uma base de igualdade suficiente está intimamente ligada ao ideal de razão pública. De fato, Rawls tem afirmado mais e mais que é o ideal de razão pública mesmo que necessita das exigências institucionais da estrutura básica, com o propósito de prevenir que se desenvolvam excessivas desigualdades sociais e econômicas.

Dessa maneira, em resumo, o argumento conforme o qual o igual acesso ao processo político requer uma garantia embutida que, na estrutura básica da sociedade, previne que igualdades sociais e econômicas se tornem excessivas em conjunção com o argumento de que as desigualdades permitidas pelo princípio da diferença não serão suficientemente inexpressivas para excluir isso conduz à conclusão de que a justiça como equidade requer medidas fortemente igualitárias. 


\section{Um sociedade justa}

A intenção originária da justiça como equidade era resolver o desacordo sobre como os valores liberdade, igualdade e fraternidade (ou reciprocidade) seriam realizados na estrutura básica da sociedade. Ao longo do tempo Rawls não desistiu da dimensão igualitária do liberalismo (político); e deveríamos entender, a partir dessa perspectiva, a pretensão de Rawls de que “a mesma concepção igualitária de antes”, isto é, de Uma Teoria da Justiça, é pressuposta.

Mas ao longo do tempo Rawls mudou sua atenção para a questão acerca de como poderíamos, exatamente, esperar atingir o acordo acerca disso sobre as razões corretas. No anos posteriores à publicação de Uma Teoria da Justiça (1971), Rawls estava mais e mais preocupado com o fato de que as modernas sociedades democráticas eram caracterizadas por uma pluralidade de incompatíveis - ainda que razoáveis - doutrinas compreensivas, religiosas, filosóficas e morais, e que nenhuma delas era afirmada, geralmente, por todos os cidadãos. Isto também explica o porquê de Rawls pretender que sua teoria seja especificamente uma teoria da justiça política, a qual é ela mesma não uma teoria moral compreensiva, nem a parte de uma. O problema é afirmado como sendo o de trabalhar uma concepção política de justiça para um regime (liberal) democrático constitucional que as pessoas possam apoiar enquanto elas, ao mesmo tempo, afirmam uma pluralidade de doutrinas compreensivas razoáveis, sendo ou religiosas ou não religiosas, ou liberais ou não liberais.

O ponto a ser notado é que Rawls está consciente, muito mais do que a maioria dos defensores da democracia liberal, do fato de que não é autoevidente que o acordo será o resultado das questões profundamente disputadas. Ele demonstra que a busca pelos termos da cooperação equitativa, os quais são razoáveis para que todos os aceitem, é uma tarefa difícil, mesmo se nos restringirmos a cidadãos razoáveis.

Mencionar a magnitude da tarefa da justificação pública não é, contudo, dizer que nós, seguindo Rawls, não devemos trabalhar duro (em nome da justiça, propriamente entendida) para convencer pessoas o suficiente sobre a importância de aderir à concepção política do liberalismo político, e, no melhor dos casos, da dimensão igualitária do liberalismo político, da justiça como equidade. Mas é realista supor que o resultado será, em verdade, 
que "você e eu", "aqui e agora", seremos convencidos da importância de aderir a esta concepção de justiça?

Tocamos, aqui, na ideia de Rawls segundo a qual uma das tarefas da filosofia política é expandir "o que é ordinariamente pensado como sendo os limites da possibilidade política praticável e, ao fazê-lo, reconciliar-nos com nossa condição política ou social” ( $L o P$. 11). Quando a filosofia política amplia, realmente, o que ordinariamente pensamos como sendo os limites do que pode ser, ela é realisticamente utópica. Ao formular as linhas gerais de uma ordem política justa, a filosofia política nos dá uma perspectiva sobre pelo que vale a pena lutar em política. Argumentos convincentes, deliberação, boas razões, todos esses elementos são essenciais para que atinjamos isto, e nos convencem da plausibilidade de que que esta utopia seja verdadeiramente realística.

Podemos tentar descobrir os valores que são necessários para construir uma justificação da justiça como equidade em certas ideias fundamentais, vistas como implícitas (latentes) na cultura política pública de uma sociedade democrática, as quais compreendem as instituições políticas de um regime constitucional e a tradição pública de sua interpretação, bem como textos políticos (constituições; declarações de direitos humanos) que são de conhecimento comum. As principais instituições da sociedade, e suas formas aceitas de interpretação, são vistas como um fundo de ideias e princípios implicitamente compartilhados. Rawls é de opinião que nós, leitores de sua obra em sociedades democráticas contemporâneas, sempre temos uma ideia implícita de justiça baseada nesse fundo compartilhado. Isso é evidente, por exemplo, na forma como, na vida diária, é debatido o sentido dos direitos e liberdades constitucionais. Algumas das ideias têm um caráter mais fundamental do que outras.

Um apelo a um fundo de ideias compartilhado, a um fórum comum, é crucial para que sejamos bem sucedidos na mudança de convicções predominantes nas ordens políticas existentes sobre o que é recíproco, aceitável, e equanime, e sermos capazes de fazer um apelo bem sucedido à imaginação política e sociológica dos cidadãos. O pensável é, muito frequentemente, condicionado pelo que parece possível. Muitas questões não são, de qualquer forma, inalcançáveis, mas desapareceram de vista. A teoria da justiça tal como formulada por Rawls oferece um exemplo de como ampliar nossa perspectiva: "o problema, aqui, é que os limites do possível não são dados pelo existente, pois podemos mudar, para uma maior ou para 
uma menor medida, as instituições políticas e sociais, e muito mais. Dessa maneira, dependemos de conjecturas e especulações, argumentando o melhor que pudermos que o mundo social que almejamos é viável e pode, realmente, existir, se não agora, então em um tempo futuro em circunstâncias felizes” (LoP: 12).

Desnecessário dizer que a ideia de 'utopia realista' é uma ideia institucional. Ela não é uma ideia nova, introduzida por Rawls ${ }^{22}$. Desde o começo ele procurou trabalhar um ideal realista de justiça. Esta é, de fato, a permanente motivação subjacente às obras de Rawls, e a ideia de uma utopia realista entrevê a culminação de seu projeto institucional. Com essa ideia fechamos o círculo, de volta ao projeto formulado em Uma Teoria da Justiça: a ideia de que a 'justiça é a primeira virtude das instituições sociais'. A teoria de Rawls formularia uma resposta sobre como projetar instituições políticas, sociais e econômicas tais que cidadãos agiriam corretamente de acordo com apropriados princípios de seu senso de justiça, os quais eles teriam adquirido por terem crescido sob instituições justas, e por destas participarem ( $L o P$. 13, nota 2).

Embora não haja garantia de que uma sociedade justa deva, ou venha a existir - como alguém poderia garantir tal coisa? -, a possiblidade de que poderia é importante. "Ao mostrar como o mundo social poderia realizar todos os aspectos de uma utopia realista, a filosofia política oferece um objetivo a longo prazo para o esforço político, e trabalhar em direção a este objetivo dá sentido ao que podemos fazer hoje” (LoP. 128).

Para nós, 'você e eu', 'aqui e agora', a questão é: nós, em nossos papéis de cidadãos, verdadeiramente endossamos as ideias de Rawls sobre 'o que a justiça requer?' Nós verdadeiramente concordamos que o fundo de ideias compartilhado abrange uma concepção igualitária forte de justiça como equidade? Não podemos ter certeza disso. Mas qualquer cidadão realmente interessado em alcançar uma sociedade mais substancialmente igualitária e justa pode adotar a justiça como equidade como um guia, e seus princípios como critérios "para avaliar as instituições e guiar a direção geral da mudança social” em nossos esforços para colocar a estrutura institucional de

\footnotetext{
${ }^{22}$ A expressão 'utopia realista' só ficou conhecida do público em geral pelo seu uso em The Law of Peoples (ver, por exemplo, LoP: 4,5-6,11-23) e pelo seu uso em Justice as Fairness: A Restatement $(\mathrm{JaF}: 4,13)$. A expressão tem, contudo, sido usada por Rawls desde o final dos anos 1980, por exemplo, em um manuscrito que continha os principais contornos para JaF, eventualmente publicada em 2001. Mas trabalhar em uma 'ideia realista de justiça' sempre foi o objetivo de Rawls.
} 
nossas atuais sociedades mais em acordo com o que é exigido pela justiça como equidade (TJ: 263; TJR: 232). Temos uma palavra a dizer quanto a como esta história termina.

\section{REFERÊNCIAS BIBLIOGRÁFICAS}

HART, H.L.A. 'Rawls on Liberty and its Priority'. University of Chicago Law Review, 40(3), 1973: 534-555.

KROUSE, R.; McPHERSON, M. 'Capitalism, 'property-owning democracy'. In: GUTMANN, A. (ed.). Democracy and the Welfare State. Princeton: Princeton University Press, 1988, p. 79-105.

LEHNING, P. B. John Rawls: An Introduction. Cambridge: Cambridge University Press, 2009.

MEADE, J. E. Efficiency, Equality, and the Ownership of Property, 40, Cambridge, MA: Harvard University Press, 1965.

RAWLS, J. Collected Papers. Edited by Samuel Freeman. Cambridge, MA: Harvard University Press, 1999.

. Justice as Fairness: A Restatement. Edited by Erin Kelly. Cambridge, MA: Harvard University Press, 2001.

- Lectures on the History of Moral Philosophy. Edited by Barbara Herman. Cambridge, MA: Harvard University Press, 2000.

. 'The Basic Liberties and Their Priority'. In: McMURRIN, Sterling M. (Ed.). Tanner Lectures on Human Values, volume III, 3-87, Salt Lake City: University of Utah Press, 1982.

. The Law of Peoples. Cambridge, MA: Harvard University Press, 1999.

. Political Liberalism. New York: Columbia University Press, 1996.

. A Theory of Justice. Cambridge, MA: Harvard University Press, 1971.

. A Theory of Justice. Revised Edition. Cambridge, MA, Harvard University Press, 1999.

- 'The Idea of Public Reason Revisited'. In: The Law of Peoples. Cambridge, MA: Harvard University Press, 1999, p. 129-180. 
SUNSTEIN, C. 'Beyond the Republican Revival'. Yale Law Journal, 97, 1988: 1539-1590.

TAYLOR, C. Philosophy and the Human Sciences. Philosophical Papers 2.335. Cambridge: Cambridge University Press, 1985.

Recebido em: julho de 2011 Aprovado em: outubro de 2011

E-mail: p.b.lehning@ext.eur.nl 